\title{
Boiling regimes in a closed two-phase thermosyphon
}

\author{
A. NIRO \\ Dipartimento di Energetica, Politecnico di Milano, Milano 20133, Italy
}

and

\section{G. P. BERETTA}

Dipartimento di Ingegneria Meccanica, Università di Brescia, Brescia 25060, Italy, and Department of Mechanical Engineering, MIT, Cambridge, MA 01239, U.S.A.

(Received 7 June 1989 and in final form 28 November 1989)

\begin{abstract}
Experimental results and an analytical model on the boiling mechanisms in a closed two-phase thermosyphon are presented in order to define the frontiers between the main boiling regimes and, in particular, the frontier between intermittent boiling and fully-developed boiling. The boiling regimes are classified on the basis of the frequency of bubble nucleation and the ratio of bubble diameter to device diameter. A criterion for the intermittent/developed-boiling frontier is based on the ratio of the bubblenucleation waiting time and the bubble growth time. From this criterion a correlation between power throughput, working-fluid pressure and nucleation critical superheat are obtained. Experimental data on operating conditions, temperatures, and nucleation frequencies show the same functional dependence as the proposed correlation.
\end{abstract}

\section{INTRODUCTION}

THE PURPOSE of this work is to study experimentally and theoretically the boiling mechanisms in a closed two-phase thermosyphon for medium and large fillings, in order to define the frontiers between the main regimes and, in particular, the frontier between intermittent boiling and fully-developed boiling.

Closed two-phase thermosyphons (or wickless heat-pipes) can operate in two different ways depending on fluid filling : the 'falling film evaporation' mode for small fillings (liquid volume less than about $10 \%$ of the evaporator volume), and 'pool boiling' for medium and large fillings (from 30 to $100 \%$ and over of the evaporator volume). In the falling-film evaporation mode all the thermosyphon walls are wetted by a continuous liquid film which, however, for most fluids is stable only at very low thermal fluxes. In the pool-boiling mode, instead, the thermosyphon evaporator is flooded, boiling is sustained over a wide range of operating fluids and conditions, and the power throughput is much greater. Therefore, pool boiling is the mode of operation of technological interest. However, there are many boiling regimes characterized by different degrees of steadiness, which affect differently the thermosyphon performance.

In the last 15 years the fluid dynamic phenomena related to mass, momentum and heat transfer between evaporator and condenser have been extensively studied in order to determine the operating limits; Imura et al. [1] reviewed about ten different relations for the flooding limit. The boiling phenomena in the evaporator have almost always been overlooked, even in some new theoretical models $[2,3]$, although instabilities and unsteady regimes have been known for a long time [4-6] to depend on the details of the boiling mechanisms. Casarosa et al. [7] clearly showed experimentally the existence of strongly intermittent boiling regimes.

To optimize the performance of a closed two-phase thermosyphon, the designer must avoid such regimes and, therefore, be aware of the causes of the unsteady behavior. Unsteady regimes cause large-amplitude oscillations in many characteristic variables, such as the evaporator wall temperature that can exceed the design values. Moreover, for evaporator fixed-temperature boundary conditions, the operation may result blocked when not expected. However, no correlations for the frontier between intermittent and fully-developed boiling are available in the literature.

In this paper, we first review the boiling regimes and the causes of unsteady operation; then, we propose criteria for classifying the main regimes and obtain analytical correlations for the intermittent/fullydeveloped-boiling frontier and slug/bubble-boiling frontier; finally, we discuss the experimental results and a diagram where the frontiers are plotted.

\section{BOILING REGIMES}

If the thermosyphon is initially isolated, the liquid is at rest in the evaporator and is in thermodynamic equilibrium with its vapor that fills the remaining volume of the device. The temperature is imposed by the heat sink, in contact with the thermosyphon 


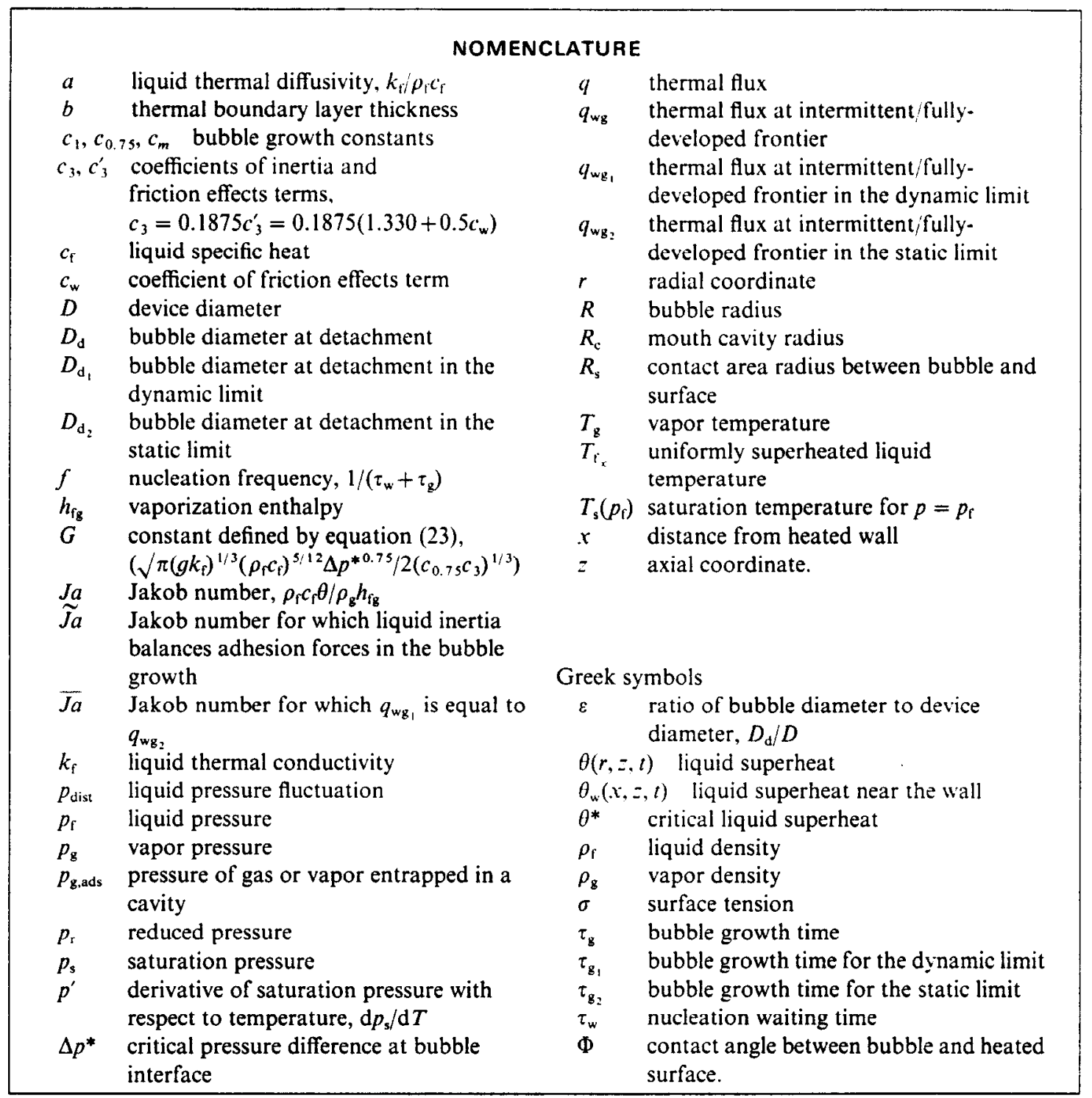

through the condenser. At time $t_{0}$ we begin to power the heat source, the liquid starts to superheat. Evaporation begins from the free surface. Boiling, instead, starts when the liquid reaches a critical superheat, i.e. a critical value of temperature greater than the saturation temperature corresponding to the pressure in the device. The critical superheat for bubble nucleation depends on the heated surface characteristics (roughness, adsorbed gases or vapors) and the thermodynamic properties of the fluid (vapor density and enthalpy of vaporization).

Depending on the extent of the critical liquid superheat, boiling may be characterized by a broad spectrum of nucleation frequencies and bubble dimensions. The nucleation frequencies can range from less than $0.01 \mathrm{~Hz}$ to more than $50 \mathrm{~Hz}$. Low nucleation frequencies $(<0.1 \mathrm{~Hz})$ bring about the intermittentboiling regime: long periods of liquid quietness (up to several hundreds of seconds) alternate with sudden and almost explosive vapor nucleations; the nucleation is generally followed by strong boiling that quickly goes out giving way to a new period of quietness. Low nucleation frequencies are related in fact to high liquid superheats that cause the formation of large bubbles with respect to the device diameter. Obviously, the lower the nucleation frequency, the more uneven and unsteady becomes the operation of the thermosyphon. High nucleation frequencies $(>10 \mathrm{~Hz}$ ) bring about the fully-dereloped boiling: thick jets of small bubbles (1-2 mm diameter) detach from one or more active cavities on the heated surface, making the fluid strongly turbulent in the evaporator. For frequencies between 0.1 and $10 \mathrm{~Hz}$ we have transition regimes characterized by intermediate bubble growth rates and bubble dimensions. A particular transition regime is the slug-developed boiling. 
characterized by nucleation frequencies of about $1 \mathrm{~Hz}$, bubble dimensions comparable with the device diameter, and a slow formation of vapor slugs. In accordance with these observations, we classify the different regimes based on the nucleation frequency and the ratio of bubble diameter to device diameter.

The boiling process consists of the sequence of the processes of bubble nucleation, growth and detachment. Experimentally we observed that nucleation in our thermosyphons always occurs at the wall. This is because the heated surface has some roughness, cavities and scratches of various sizes that become active if some gas or vapor is entrapped. In a uniformly superheated liquid, nucleation occurs at an active cavity when the liquid reaches the critical superheat

$$
\theta^{*} \approx \frac{1}{\mathrm{~d} p_{\mathrm{s}} / \mathrm{d} T} \Delta p^{*}
$$

where $\Delta p^{*}$ is the difference between vapor pressure and liquid pressure when the nucleus reaches the critical dimensions. From equation (1) we see that for a given $\Delta p^{*}$ the lower $\mathrm{d} p_{\mathrm{s}} / \mathrm{d} T$ the higher the critical superheat. For example, for water $\mathrm{d} p_{\mathrm{s}} / \mathrm{d} T$ decreases by a factor of 50 between 120 and $20^{\circ} \mathrm{C}$ and, therefore, the superheats needed for nucleation at $20^{\circ} \mathrm{C}$ are 50 times higher than at $120^{\circ} \mathrm{C}$. Thus, the critical superheat $\theta^{*}$ is a function of the pressure $p$ (since $\mathrm{d} p_{\mathrm{s}} / \mathrm{d} T$ is a monotonic function of $p_{\mathrm{s}}$ ) and increases as pressure decreases. Because the hypothesis of uniform liquid superheat is not actually verified, we further assume (as suggested by Hsu [8]) that the critical superheat $\theta^{*}$ is reached by a liquid layer of thickness $b$ near the heated wall. For $b$ we assume the value $1.5 R_{\mathrm{c}}$ proposed by Han and Griffith [9].

We define the waiting time $\tau_{w}$ as the time needed to attain the critical superheat $\theta^{*}$ in the layer of thickness $b$. The waiting time ends and the growth time $\tau_{\mathrm{g}}$ begins when the vapor nucleus, after reaching the critical dimension, starts to grow quickly. The growth time ends when the bubble detaches from the heated surface. The inverse of the period of a whole cycle, i.e. of the sum of the waiting time and the growth time is defined by Han and Griffith [9] as the nucleation frequency

$$
f=\frac{1}{\tau_{w}+\tau_{g}} .
$$

For $\tau_{w}$ much longer than $\tau_{g}$, the nucleation frequency obviously coincides with the inverse of the waiting time.

\section{INTERMITTENT VS FULLY-DEVELOPED. BOILING FRONTIER}

We say that boiling is 'fully developed' when the waiting time $\tau_{w}$ is much shorter than the growth time $\tau_{\mathrm{g}}$, whereas boiling is 'intermittent' when the waiting time $\tau_{w}$ is much longer than the growth time $\tau_{\mathrm{g}}$. Thus, the transition frontier between the intermittent-boiling regime and the fully-developed-boiling regime is determined by the criterion

$$
\tau_{\mathrm{w}} \sim \tau_{\mathrm{g}} .
$$

In order to derive from criterion (3) a relation between fluid thermodynamic properties, geometric characteristics and system boundary conditions, we need to estimate $\tau_{w}$ and $\tau_{g}$.

\subsection{Determination of $\tau_{w}$}

The waiting time $\tau_{w}$ can be determined by the general nucleation criterion

$$
\theta\left(R-b, z_{\mathbf{s}}, \tau_{\mathrm{w}}\right)=\theta^{*}
$$

where $\theta(r, z, t)$ describes in cylindrical coordinates the liquid superheat as a function of the distance $r$ from the evaporator axis, the height $z_{\mathrm{s}}$ in the evaporator of the nucleation site, and time $t$. The liquid superheat near the heated surface is determined by three contributions: (a) the thermal boundary layer; (b) the bulk heating of the liquid in the evaporator; and (c) the cooling of the vapor in the condenser which reduces the vapor temperature and, hence, the saturation pressure and temperature. However, the characteristic times of the three superheat contributions are quite different: the boundary-layer characteristic time is of the order of $0.1 \mathrm{~s}$ and is much shorter than the characteristic times of the other two contributions (b) and (c) which are of the order of 10 $\mathrm{s}$ as reported in ref. [10]. Since the bubble growth time $\tau_{\mathrm{g}}$ is always shorter than $200 \mathrm{~ms}$ and, by virtue of criterion (3), the waiting time $\tau_{w}$ at the transition frontic $r$ is of the same order of magnitude as $\tau_{g}$, we can consider only the thermal boundary layer contribution $\theta_{w}$ and neglect the other two contributions. We express $\theta_{w}$ more conveniently in Cartesian coordinates, i.e. $\theta_{w}=\theta_{w}(x, z, t)$ where $x$ is the distance from the heated wall. We have observed experimentally that liquid mixing due to boiling is equally effective at all heights in the evaporator at the transition frontier. Hence, we assume that the heat transfer coefficient and therefore the liquid superheat at the wall $\theta_{w}$, for fixed thermal flux boundary conditions, depend weakly on height $z$. Equation (4) becomes

$$
\theta_{w}\left(b, \tau_{w}\right)=\theta^{*} \text {. }
$$

Finally because the convection intensity near the solid wall is dumped down due to the no-slip boundary condition, we may assume as suggested by Han and Griffith [9] a purely conductive heat transfer mechanism in the liquid near to the heated wall. Accordingly, the waiting time may be approximated by

$$
\tau_{w}=\frac{\pi}{4}\left(1+\frac{b q}{k_{\mathrm{f}} \theta^{*}}\right)^{2} k_{\mathrm{f}} \rho_{\mathrm{f}} c_{\mathrm{f}} \frac{\theta^{* 2}}{q^{2}}
$$

obtained by linearizing the pure conduction solution for a semiinfinite geometry and fixed thermal flux boundary conditions. 


\subsection{Determination of $\tau_{g}$}

To determine the growth time we need the bubble growth law and the force balance that controls bubble detachment from the heated surface. At the detachment instant, the force balance is

$$
F_{\mathrm{b}}=F_{\mathrm{s}}+F_{\mathrm{ib}}+F_{\mathrm{f}}
$$

i.e. buoyancy $\left(F_{\mathrm{b}}\right)$ balances surface adhesion forces $\left(F_{s}\right)$, liquid inertia $\left(F_{11}\right)$ and viscous drag $\left(F_{f}\right)$. We observed experimentally (with a high speed camera) that the shape of the growing bubble is nearly spherical (also for high superheat). Thus, the balance (7) may be written as

$$
{ }_{3}^{4} \pi R^{3} \rho_{\mathrm{r}} g=2 \pi \sigma R_{\mathrm{s}} \sin \Phi+\frac{4}{3} \pi R^{2} \dot{R}^{2} \rho_{\mathrm{f}}+\frac{c_{\mathrm{w}}}{2} \pi R^{2} \dot{R}^{2} \rho_{\mathrm{f}}
$$

where $R_{\mathrm{s}}$ is the contact radius between bubble and surface (assumed to be constant and independent of the bubble radius $R$ ), $\dot{R}$ the bubble detachment velocity (the bubble is assumed to be tangent to the heated surface), $c_{\mathrm{w}}$ an empirical drag coefficient, as reported in refs. $[11,12]$, since the friction forces are not sufficiently known. The angle $\Phi$ should be the contact angle between bubble and heated surface for a horizontal surface. Here we assume that $\Phi$ includes also a geometry factor, taking into account that our surface is vertical. The inertia term is derived from the Witze et al. [13] solution, obtained for a spherical bubble growing tangent to the surface in semiinfinite liquid and for inviscid and irrotational flow. The assumption of semiinfinite liquid implies that balance (8) holds only for small bubbles with respect to the device diameter. This assumption is further discussed later. Inertia forces and viscous forces have the same functional dependence from $R$ and $\dot{R}$, and may be grouped in a single term $c_{3}^{\prime} \pi R^{2} \dot{R}^{2} \rho_{f}$, where $c_{3}^{\prime}=$ $\left(1.333+0.5 c_{\mathrm{w}}\right)$.

Determining the bubble growth law as a function of liquid superheat and thermodynamic properties is a hard problem. For small superheats and a pressure not much lower than atmospheric, the growth is wholly controlled by the heat transfer mechanisms (negligible liquid inertia). In the limit of negligible inertia we find the so-called 'asymptotic solution'

$$
R=c_{1} J a \sqrt{ }(a t)
$$

where $J a$ is the Jakob number, $J a=\rho_{\mathrm{f}} c_{\mathrm{f}} \theta / \rho_{\mathrm{g}} h_{\mathrm{fg}}$, and $a$ the liquid diffusivity, $a=k_{\mathrm{f}} / \rho_{\mathrm{r}} c_{\mathrm{f}}$. The range of validity of equation ( $\left(^{\prime}\right)$ is discussed in the Appendix.

When the inertia effects are not negligible, equation $\left(9^{\prime}\right)$ ceases to hold and the bubble growth law becomes complex [14-16]. Since we need an analytical expression, we use the empirical growth equation proposed by Cole and Shulman [17]

$$
R=c_{0.79} J a^{0.75} \sqrt{ }(a t)
$$

The range of validity for equation $\left(9^{\prime \prime}\right)$ is also discussed in the Appendix. Both equations $\left(9^{\prime}\right)$ and $\left(9^{\prime \prime}\right)$ can be written in the form

$$
R=c_{m} J a^{m} \sqrt{(a t)}
$$

Using equation (10) in balance (8), we obtain the growth time

$\tau_{\mathrm{g}}=\left(c_{m} c_{3}\left(\frac{a}{g^{2}}\right)^{1 / 2} J a^{m}+\frac{3 \sigma R_{\mathrm{s}} \sin \Phi}{2 \rho_{\mathrm{r}} g c_{m}^{3} J a^{3 m} a^{1.5}}\right)^{2 ; 3}$

where $c_{3}=0.1875 c_{3}^{\prime}$. The first term within parentheses is the ratio between dynamical forces (liquid inertia and viscous drag) and buoyancy; the second term is the ratio between surface adhesion force and buoyancy. Equation (11) has two interesting limit solutions

$$
\begin{aligned}
\tau_{\mathrm{g}_{1}} & =\left(c_{m} c_{3}\right)^{2 / 3}\left(\frac{a}{g^{2}}\right)^{1 / 3} J a^{(2 / 3) m} \\
\tau_{\mathrm{g}_{2}} & =\left(\frac{3 \sigma R_{\mathrm{s}} \sin \Phi}{2 \rho_{\mathrm{f}} g}\right)^{2 / 3} \frac{1}{c_{m}^{2} J a^{2 m} a} .
\end{aligned}
$$

Equation (12), called the dynamic limit solution, holds when liquid inertia prevails over adhesion forces, i.e. when

$$
c_{m} c_{3} J a^{m}\left(\frac{a}{g^{2}}\right)^{1,2} \gg \frac{3 \sigma R_{\mathrm{s}} \sin \Phi}{2 \rho_{\mathrm{r}} g c_{m}^{3} J a^{3 m} a^{1.5}}
$$

or, equivalently

$$
J a \gg\left(\frac{3 \sigma R_{\mathrm{s}} \sin \Phi}{2 p_{\mathrm{f}} g} \frac{1}{c_{m}^{4} c_{3}} \frac{g}{a^{2}}\right)^{1 / 4 m}=\widetilde{J a} .
$$

Equation (13), called the static limit solution, holds when adhesion forces prevail over liquid inertia, i.e. when

$$
J a \ll \widetilde{J} a .
$$

\subsection{Intermittent/fully-developed-boiling frontier cor- relation}

Substituting relations (6) and (11) in criterion (3), and assuming that the term $\left(b q / k_{i} \theta^{*}\right)$ in equation (6) is negligible, we find the equation

$$
\begin{aligned}
& q_{\mathrm{wg}}=\frac{\sqrt{ }\left(\pi k_{\mathrm{c}} \rho_{\mathrm{f}} c_{\mathrm{f}}\right)}{2} \\
& \times \frac{\theta^{*}}{\left(c_{m} c_{3}\left(\frac{a}{g^{2}}\right)^{1 / 2} J a^{m}+\frac{3 \sigma R_{\mathrm{s}} \sin \Phi}{2 \rho_{\mathrm{f}} g c_{m}^{3} J a^{3 m} a^{1.5}}\right)^{1.3}}
\end{aligned}
$$

that gives the thermal flux $q_{\mathrm{wg}}$ at the transition frontier between intermittent boiling and fully-developed boiling, as a function of critical liquid superheat $\theta^{*}$ (and, therefore, of pressure $p$ ) and fluid thermodynamic properties. We see that boiling is 'fully developed', i.e. $\tau_{w} \ll \tau_{\mathrm{g}}$, when $q \gg q_{\mathrm{wg}}$.

In the dynamic limit ( $J a \gg \widetilde{J a}$ ) and the static limit $(J a \ll \widetilde{J} a)$, equation $(15)$ can be simplified, respectively, to yield 


$$
\begin{gathered}
q_{\mathrm{wg}_{1}}=\frac{\sqrt{ } \pi}{2\left(c_{0.75} c_{3}\right)^{1 / 3}}\left(g k_{\mathrm{f}}\right)^{1 / 3}\left(\rho_{\mathrm{f}} c_{\mathrm{f}}\right)^{5 / 12} \frac{\Delta p^{* 0.75} T^{0.25}}{\sqrt{ } p^{\prime}} \\
q_{\mathrm{wg}_{2}}=\frac{\sqrt{ } \pi}{2} c_{1} k_{\mathrm{f}} \rho_{\mathrm{f}} c_{\mathrm{f}}\left(\frac{2 \rho_{\mathrm{f}} g}{3 \sigma R_{\mathrm{g}} \sin \Phi}\right)^{1 / 3} \frac{\Delta p^{* 2}}{p^{\prime 3} T}
\end{gathered}
$$

where $T$ is the saturation temperature corresponding to the pressure of the liquid, i.e. $T \equiv T_{s}\left(p_{t}\right)$, and $p^{\prime}$ denotes $\left(\mathrm{d} p_{\mathrm{s}} / \mathrm{d} T\right)_{T=T_{i}\left(p_{f}\right)}$. Equations (16) and (17) are obtained using, respectively, equations $\left(9^{\prime \prime}\right)$ and $\left(9^{\prime}\right)$, and the equation

$$
J a=\frac{\rho_{\mathrm{f}} c_{\mathrm{f}}}{\rho_{\mathrm{g}} h_{\mathrm{fg}}} \theta=\frac{\rho_{\mathrm{f}} c_{\mathrm{f}}}{p^{\prime 2} T} \Delta p
$$

derived by replacing in the Jakob number equation (1) $\left(\theta \approx \Delta p / p^{\prime}\right)$ and the Clausius-Clapeyron equation $\left(\mathrm{d} p_{\mathrm{s}} / \mathrm{d} T=p^{\prime} \approx \rho_{\mathrm{g}} h_{\mathrm{fg}} / T\right)$.

It is interesting to point out that at the transition frontier the functional dependence of the thermal flux $q_{\mathrm{wg}}$ on the critical superheat $\theta^{*} \approx\left(\Delta p^{*} / p^{\prime}\right) \sim 1 / p^{\prime}$ ranges from $q_{\mathrm{wg}} \sim \theta^{* 0.5}$ to $q_{\mathrm{wg}} \sim \theta^{* 3}$ depending on whether the bubble growth is dominated by dynamic forces or static forces. If dynamic forces dominate, bubbles are not frequent and not small enough to yield bubble-fully-developed boiling; thus the functional dependence of $q_{\mathrm{wg}}$ on $\theta^{*}$ is not what we have in bubblefully-developed boiling.

\section{SLUG VS BUBBLE-BOILING FRONTIER}

The regimes are characterized not only by the nucleation frequency $f=1 /\left(\tau_{w}+\tau_{g}\right)$, but also by the bubble dimensions $D_{\mathrm{d}}$ with respect to the device diameter $D$. For the same nucleation frequency and bubble dimension we may have different regimes depending on the device diameter, according to the three criteria

$$
D_{\mathrm{d}} / D \ll 1, \quad D_{\mathrm{d}} / D \sim 1, \quad D_{\mathrm{d}} / D \gg 1 .
$$

The criterion $D_{\mathrm{d}} / D \ll 1$ identifies bubbles that are very small; the criterion $D_{\mathrm{d}} / D \sim 1$ identifies bubbles with dimensions that are comparable with the device diameter (slugs); and the criterion $D_{\mathrm{d}} / D \gg 1$ identifies very large bubbles (long slugs).

In order to derive from criteria (19) analytical relations, we need to estimate $D_{\mathrm{d}}$. Substituting equations (11)-(13) in the growth law equation (10), we get the bubble diameter at detachment $D_{\mathrm{d}}$, respectively, for the general case and the two limit solutions (dynamic and static), i.e.

$$
\begin{aligned}
& D_{\mathrm{d}}=2\left(c_{m}^{4} c_{3}\left(\frac{a^{2}}{g}\right) J a^{4 m}+\frac{3 \sigma R_{\mathrm{s}} \sin \Phi}{2 \rho_{\mathrm{s}} g}\right)^{1 / 3} \\
& D_{\mathrm{d}_{1}}=2 c_{m}^{4 / 3} c_{3}^{1 / 3}\left(\frac{a^{2}}{g}\right)^{1 / 3} J a^{(4 / 3) m} \quad J a \gg \widetilde{J a} \\
& D_{\mathrm{d}_{2}}=2\left(\frac{3 \sigma R_{\mathrm{s}} \sin \Phi}{2 \rho_{\mathrm{s}} g}\right)^{1 / 3} \quad J a \ll \widetilde{J a} .
\end{aligned}
$$

For $R_{\mathrm{s}}=0.5 D_{\mathrm{d}_{2}} \sin \Phi$, equation $\left(20^{\prime \prime}\right)$ becomes the known Fritz-Hende equation. Substituting equation (20) in the ratio $D_{\mathrm{d}} / D=\varepsilon$, we find the equation

$$
J a_{\varepsilon}=\left(\frac{\varepsilon^{3} D^{3}-R_{\mathrm{d}_{2}}^{3}}{8 c_{m}^{4} c_{3}\left(a^{2} / g\right)}\right)^{1 / 4 m}
$$

or, equivalently

$p^{\prime 2} T=\frac{\rho_{\mathrm{f}} c_{\mathrm{f}}}{J a_{\mathrm{s}}} \Delta p^{*}=\left(\frac{8 c_{m}^{4} c_{3}\left(a^{2} / g\right)}{\varepsilon^{3} D^{3}-R_{\mathrm{d}_{2}}^{3}}\right)^{1 / 4 m} \rho_{\mathrm{f}} c_{\mathrm{f}} \Delta p^{*}$

obtained by replacing equation (18) in equation (21). For $\varepsilon=1$ equation (22) gives the operating pressure $p$ (that is a monotonic function of $p^{\prime}$ and $T$ ) at the transition frontier between slug boiling and bubble boiling as a function of fluid thermodynamic properties.

We say that boiling is bubble-fully-developed when equation (22) is verified for $\varepsilon \ll 1$ with $q \gg q_{w g}$ (where $q_{\mathrm{wg}}$ is given by equation (15)). The boiling is slug-fullydeveloped when equation (22) is verified for $\varepsilon \sim 1$ with $q \gg q_{\mathrm{wg}}$; whereas it is slug-developed if equation (22) is verified for $\varepsilon \sim 1$ with $q \sim q_{\mathrm{wg}}$. Finally, for $\varepsilon=D_{\mathrm{d}} / D \gg 1$ equation (22) is not verified with $q \geqslant q_{\mathrm{wg}}$ but only with $q<q_{\mathrm{wg}}$ and, therefore, corresponds to a low-frequency boiling regime.

It is noteworthy that the use of equation (20) in the criteria $D_{\mathrm{d}} / D \sim 1$ and $D_{\mathrm{d}} / D \gg 1$ and, therefore, the use of equation (22) for $\varepsilon \geqslant 1$, would yield only qualitative results because equation (20) implies the assumption $D_{\mathrm{d}} / D \ll 1$.

\section{EXPERIMENTAL RESULTS}

The aim of the experimental study was to gather information about the boiling regimes and the transition frontier between intermittent boiling and fullydeveloped boiling. To this end, we studied the trend of nucleation frequencies as a function of pressure and power throughput.

The experimental results were obtained with a specifically designed facility equipped with transparent pipes of 12 and $30 \mathrm{~mm}$ i.d. and $1000 \mathrm{~mm}$ long. The evaporator, adiabatic section and condenser were respectively 200,400 and $400 \mathrm{~mm}$ long. The evaporator was electrically heated by a nickel-chrome ribbon externally wound around it. Liquid and vapor temperatures were measured by thermocouples directly exposed to the fluid and placed respectively at $50 \mathrm{~mm}$ from the evaporator bottom and $300 \mathrm{~mm}$ from the condenser top. The input and output power and the fluid pressure were also measured. Errors on temperature measurements were less than $0.1^{\circ} \mathrm{C}$. Errors on measurements of input power, output power and pressure were respectively 15,5 and $0.5 \%$. The relatively high error on the input power measurement is due to the lack of thermal insulation around 


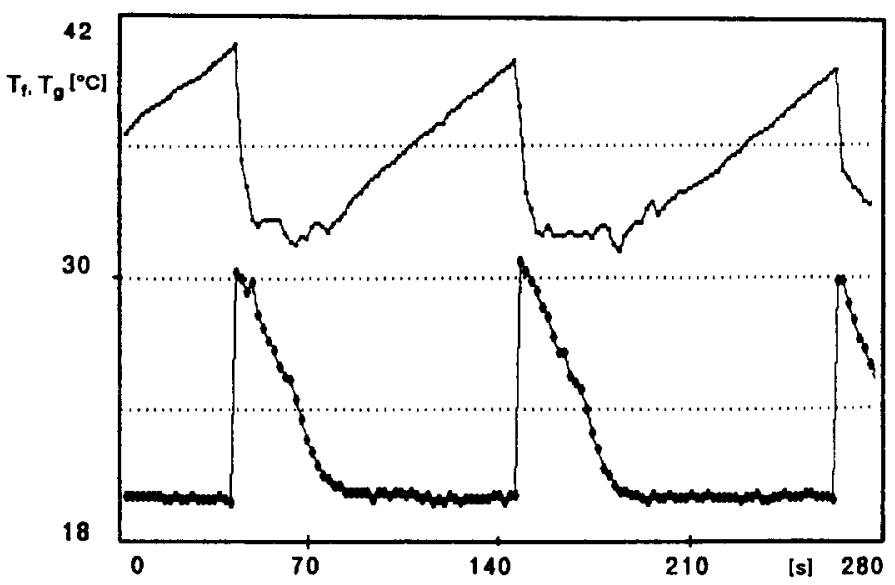

FiG. 1. Liquid and vapor temperature in a low-frequency boiling regime. $D=12 \mathrm{~mm}$; fluid, water; $p_{\mathrm{r}}=10^{-4}$ and $\dot{Q}=13 \mathrm{~W}$.

the evaporator. All measures were sampled automatically by an on-line computer at a maximum rate of $10 \mathrm{~Hz}$. A video-recording of the thermosyphon operation was also performed by a video-camera and a stroboscope (the camera recording frequency was $50 \mathrm{~Hz}$, but each frame was exposed for only $10 \mu \mathrm{s}$ ).

The thermosyphons were operated vertically. Most tests were run with water as the working fluid, some were run with acetone. The liquid filling corresponds to $80 \%$ of the evaporator volume. To span the transition between intermittent and fully-developed boiling, the operating conditions were varied so that the fluid pressure, expressed as reduced pressure, ranged between $10^{-4}$ and $10^{-2}$. The tests were grouped in sequences carried out by changing the power throughput while holding the pressure at a fixed constant value different for every sequence.

A typical trend of liquid temperature (higher graph) and vapor temperature (lower graph) in a low-frequency boiling regime (about $0.01 \mathrm{~Hz}$ ) is shown in Fig. 1, where the waiting phase and the boiling phase can be clearly recognized. During the waiting phase, evaporator and condenser are weakly coupled. The liquid at rest in the evaporator is superheating, and the vapor in the condenser is cooling. The liquid temperature at the bottom of the evaporator rises almost linearly, whereas the vapor temperature in the condenser falls almost exponentially, as shown by Fig. 2 , with a measured characteristic time of about $10 \mathrm{~s}$, approaching the condenser wall temperature. When the critical superheat is achieved, vapor nucleation occurs. Due to the high available superheat, the bubble growth rate and its dimensions are so large that the liquid above the nucleation site is suddenly and violently ejected into the condenser. This causes a sharp rise of the condenser temperature and a corresponding fall of the liquid temperature. The final vapor temperature is lower than the measured liquid temperature because this is measured at the bottom of the evaporator where it is higher due to stratification built up during the waiting time. The liquid temperature decreases due to mixing of the liquid remaining in the evaporator with the cooled liquid returning from the condenser. After the first burst,

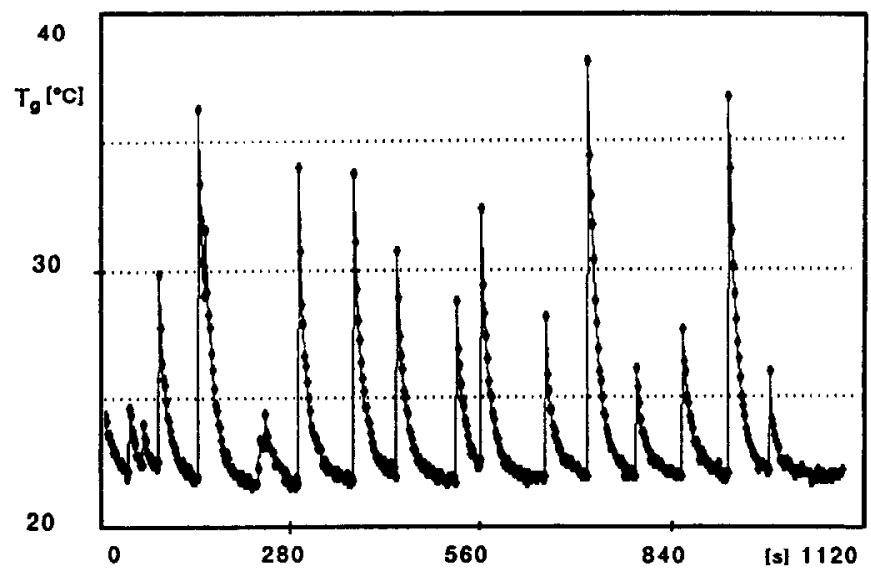

FIG. 2. Liquid and vapor temperature in a low-frequency boiling regime. $D=12 \mathrm{~mm}$ : fluid, water; $p_{\mathrm{r}}=10^{-4}$ and $\phi=32 \mathrm{~W}$. 
nucleation continues with decreasing intensity, stimulated by pressure perturbations. As the pressure perturbations weaken, boiling dies out and a new waiting phase begins. The dynamically controlled nucleation, in fact, unlike thermally controlled nucleation is not stable. The pressure in the thermosyphon always remains very close to the saturation pressure corresponding to the temperature of the vapor.

As the power throughput is increased, the critical superheat is attained in a shorter time and the waiting time between two successive bursts decreases, i.e. the burst frequency increases. As the burst frequency increases, non-linear phenomena such as pressure perturbations appear. These phenomena favor the nucleation and cooperate to further increasing the average nucleation frequency. The sequence shown in Figs. 3(a)-(d) are examples of transition between lowfrequency boiling and fully-developed boiling. The
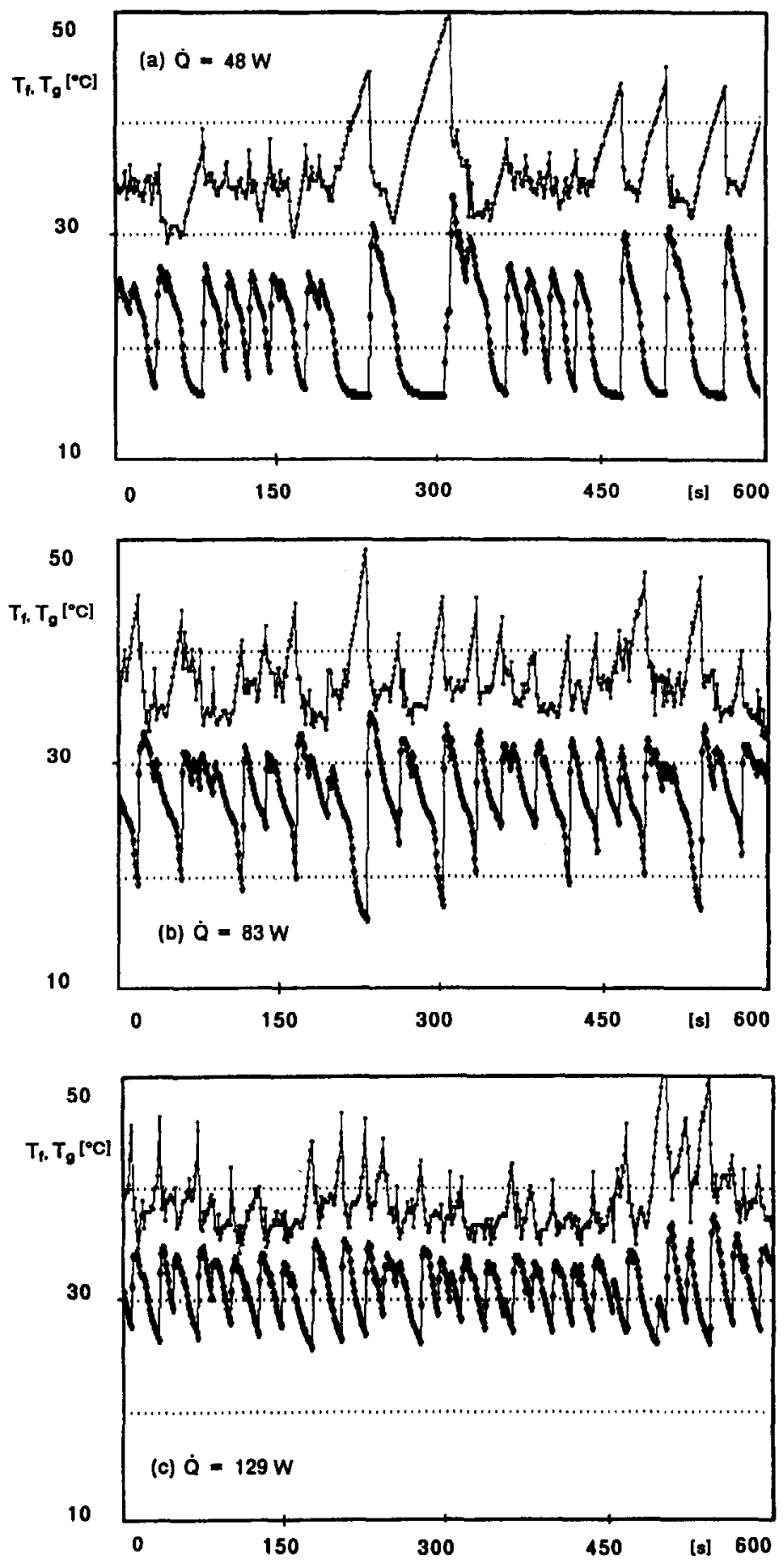

FIG. 3. Liquid and vapor temperatures in a transition between low-frequency boiling and fully-developed boiling. $D=12 \mathrm{~mm}$; fluid, water; $p_{\mathrm{r}}=10^{-4}$. 


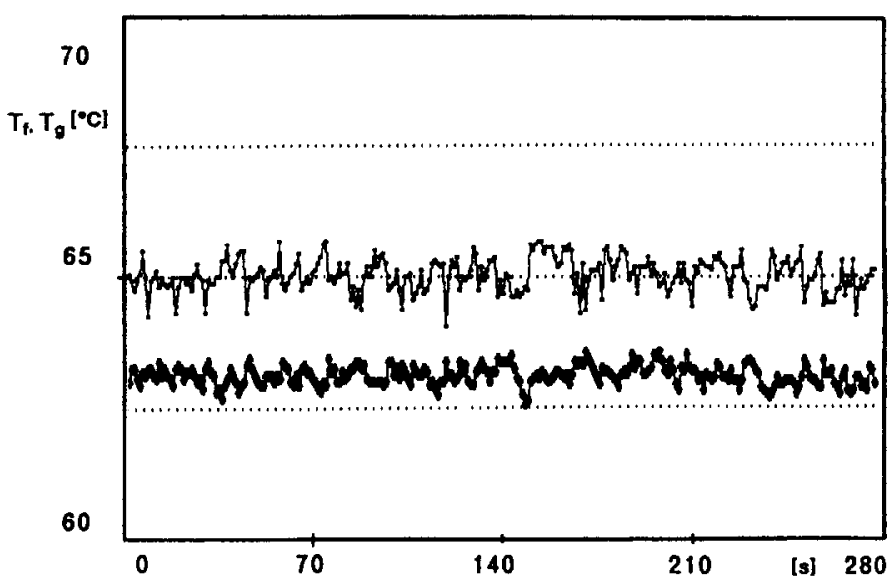

FIG. 4. Liquid and vapor temperatures in fully-developed boiling. $D=12 \mathrm{~mm}$; fluid, water; $p_{\mathrm{r}}=10^{-3}$ and $\dot{Q}=250 \mathrm{~W}$.

trend of liquid and vapor temperatures in fullydeveloped boiling is shown in Fig. 4. The temperatures still experience fluctuations, but these are restrained in $0.5^{\circ} \mathrm{C}$ for the liquid and $0.8^{\circ} \mathrm{C}$ for the vapor. These fluctuations, which remain also at high nucleation frequencies, are due to the intrinsically stochastic nature of boiling.

The thermosyphon operation is steady only 'on average', i.e. for a given pressure and power throughput, there is no single nucleation frequency, but a spectrum of frequencies which are related to phenomena such as stimulated nucleation and random operation decoupling. Thus, for each test we need to recognize a characteristic nucleation frequency. We conjecture that information about nucleation frequencies may be inferred by a spectral analysis of liquid or vapor temperatures. In this respect, we note that the vapor conditions are much more uniform than the liquid conditions and thus the vapor temperature is more suitable for this kind of analysis.

The estimate of the longer waiting times $\left(t_{w} \geqslant 10\right.$ s), such as for the traces in Fig. 2, is carried out as follows. The waiting period starts when the measured vapor temperature begins to fall exponentially, i.e. when the evaporator and the condenser decouple. The waiting period ends when the vapor temperature, after falling below a low-threshold value predetermined for each run on the basis of a visual and a statistical analysis of the traces, has a jump greater than a threshold amplitude. When this occurs, a boiling burst couples the condenser to the evaporator again. The low-threshold temperature is chosen as the temperature below which the vapor stays for $63.2 \%$ of the test time. To estimate the shorter waiting times $\left(\tau_{\mathrm{w}}<10 \mathrm{~s}\right.$ but greater than or equal to $0.5 \mathrm{~s}$ that is the minimum significant time interval consistent with our sampling rate), such as for the traces in Fig. 3(c), only temperature oscillations of amplitude smaller than a threshold amplitude are considered, i.e. we do not consider the longer random operation decouplings. For each test, we determine the average

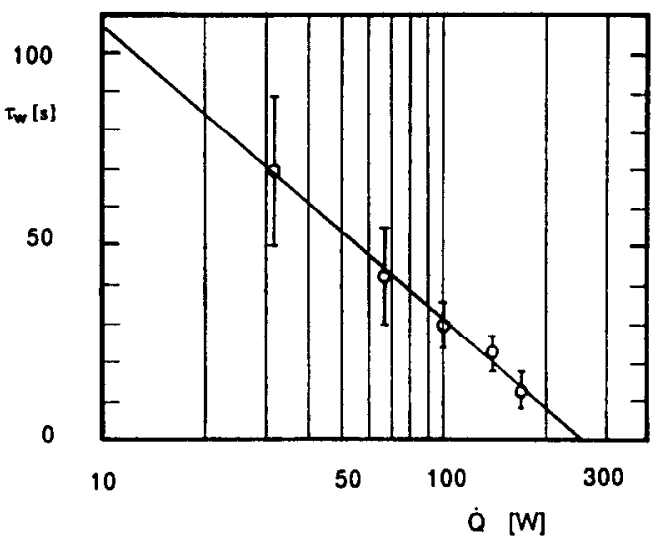

FIG. 5. Dependence of the average waiting time on power throughput. $D=12 \mathrm{~mm}$; fluid, water: $p_{\mathrm{r}}=10^{-4}$. $\phi(0)=250 \mathrm{~W}$, correlation coefficient $r=0.996$.

value and the variance of the waiting time. Elimination-inclusion procedures have also been performed in order to minimize the variance.

Figure 5 shows the dependence of the average waiting times $\tau_{w}$ on power throughput $\dot{Q}$ in a semilogarithmic scale; the graph refers to a given value of the pressure. Extrapolation of these data to zero waiting time yields a value of power throughput that we take as indicative of the minimum power needed at the given pressure for the onset of fully-developed boiling. The values of power throughput determined in this way are given in Table 1 . The data show a strong dependence on $1 / \sqrt{ } p^{\prime}$, specifically, the same functional dependence as our equation (16) for the intermittent/fully-developed-boiling frontier in the dynamic limit. Assuming that the variations of properties $\rho_{f}, c_{\mathrm{f}}$ and $k_{\mathrm{f}}$ with temperature are negligible between 20 and $80^{\circ} \mathrm{C}$, if $\Delta p^{*}$ is constant for all runs, then equation (16) may be written as

$$
q_{\mathrm{wg}_{1}}=G \frac{T^{0.25}}{\sqrt{p^{\prime}}}
$$


Table 1. Data on intermittent/fully-developed-boiling frontier

\begin{tabular}{|c|c|c|c|c|c|c|c|c|}
\hline$p_{\mathrm{r}}$ & $\begin{array}{c}T \\
\left({ }^{\circ} \mathrm{C}\right)\end{array}$ & $\begin{array}{c}T \\
(\mathbf{K})\end{array}$ & $\begin{array}{c}\mathrm{d} p_{s} / \mathrm{d} T \\
(\mathrm{SI})\end{array}$ & $J a \dagger$ & $\underset{(W)}{Q}$ & $\left(\mathrm{~W}^{q} \mathrm{~m}^{-2}\right)$ & $\begin{array}{c}T^{0.25} / \sqrt{ } P^{\prime} \\
(\mathrm{SI})\end{array}$ & Notes \\
\hline $10^{-4}$ & 19 & 292 & 138 & 508 & 250 & $3.316 \times 10^{4}$ & 0.351 & $\mathrm{D} 12-\mathrm{H}_{2} \mathrm{O}$ \\
\hline $10^{-4}$ & 19 & 292 & 138 & 508 & 230 & $3.050 \times 10^{4}$ & 0.351 & $\mathrm{Dl} 2-\mathrm{H}_{2} \mathrm{O}$ \\
\hline $10^{-4}$ & 19 & 292 & 138 & 508 & 500 & $2.653 \times 10^{4}$ & 0.351 & $\mathrm{D} 3 \mathrm{U}-\mathrm{H}_{2} \mathrm{O}$ \\
\hline $3 \times 10^{-4}$ & 38 & 311 & 359 & 70 & 150 & $1.989 \times 10^{4}$ & 0.221 & $\mathrm{D} 12-\mathrm{H}_{2} \mathrm{O}$ \\
\hline $3 \times 10^{-4}$ & 38 & 311 & 359 & 70 & 400 & $2.122 \times 10^{4}$ & 0.221 & $\mathrm{D} 30-\mathrm{H}_{2} \mathrm{O}$ \\
\hline $10^{-3}$ & 62 & 335 & 995 & 8 & 100 & $1.325 \times 10^{4}$ & 0.136 & $\mathrm{D} 12-\mathrm{H}_{2} \mathrm{O}$ \\
\hline $10^{-3}$ & 62 & 335 & 995 & 8 & 200 & $1.061 \times 10^{4}$ & 0.136 & $\mathrm{D} 30-\mathrm{H}_{2} \mathrm{O}$ \\
\hline $5 \times 10^{-3}$ & 20 & 293 & 1033 & 3 & 100 & $1.325 \times 10^{4}$ & 0.129 & D12 Acetone \\
\hline
\end{tabular}

† The Jakob numbers are estimated using the value $\Delta p=670 \mathrm{~Pa}$.

where

$$
G=\frac{\sqrt{ } \pi\left(g k_{\mathrm{f}}\right)^{1 / 3}\left(\rho_{\mathrm{f}} c_{\mathrm{f}}\right)^{5 / 12} \Delta p^{* 0.75}}{2\left(c_{0.75} c_{3}\right)^{1 / 3}}
$$

is a dimensional constant. As shown in Fig. 6, the experimental data correlate linearly with $T^{0.25} / \sqrt{ } p^{\prime}$ in a $\log -\log$ plot, with a correlation coefficient $r=0.976$ and a scatter less than or equal to $20 \%$. For the constant $G$ we find the value of $G=89670$ (all variables in SI units). Therefore, the data seem to imply that $\Delta p^{*}$ is approximately constant. Using the values $c_{0.75}=2$ and $c_{3}=1.228$, as reported in the Appendix, and $G=89670$ we find $\Delta p^{*}=670 \mathrm{~Pa}$. Using this value we estimate the Jakob numbers given in Table 1. These values and the corresponding values of liquid superheat are lower than might be expected from standard boiling experiments at the same pressure. But our experimental conditions are different. Our geometry is quite constrained and, especially as we approach fullydeveloped boiling, the turbulence generated by the flow of other bubbles causes strong pressure fluctuations. As a result of these fluctuations, it is reasonable to expect that bubbles reach critical dimensions at much lower superheats than in standard experiments.
We can express this by writing

$$
\Delta p^{*}=\frac{2 \sigma}{R_{\mathrm{c}}}-p_{\mathrm{g} . \mathrm{ads}}-p_{\mathrm{dist}}
$$

where $R_{\mathrm{c}}$ is the mouth cavity radius (we assume a hemispherical critical nucleus with a radius equal to $R_{\mathrm{c}}$ as suggested by Griffith and Wallis [18]), $p_{\text {g.ads }}$ the pressure of the gas or vapor entrapped in the cavity and $p_{\text {dist }}$ the amplitude of the liquid pressure fluctuations due to the detachment and the flow of other bubbles.

Figure 7 shows the experimental data and relations (16) and (17) on a $p^{\prime}-q$ diagram. In equation (17) for the radius at detachment (static limit) $R_{\mathrm{d}}$, we used the value $R_{\mathrm{d}_{2}}=0.30 \mathrm{~mm}$ taken from Kiper [19]. Equations (16) and (17) refer to the transition frontier in the dynamic and the static limit, respectively. The intersection point of these two limit solutions occurs for $J a=\overline{J a} \approx 7$. At that point the power is overestimated by $30 \%$ compared to that given by the complete solution (equation (15)) ; however, for $J a<18$ and $J a>4$ (i.e. for $p^{\prime}<700$ and $p^{\prime}>1400$ ) this error becomes less than $4 \%$. Thus, the two limit solutions give a good approximation of the frontier between the intermittent and fully-developed boiling regimes.

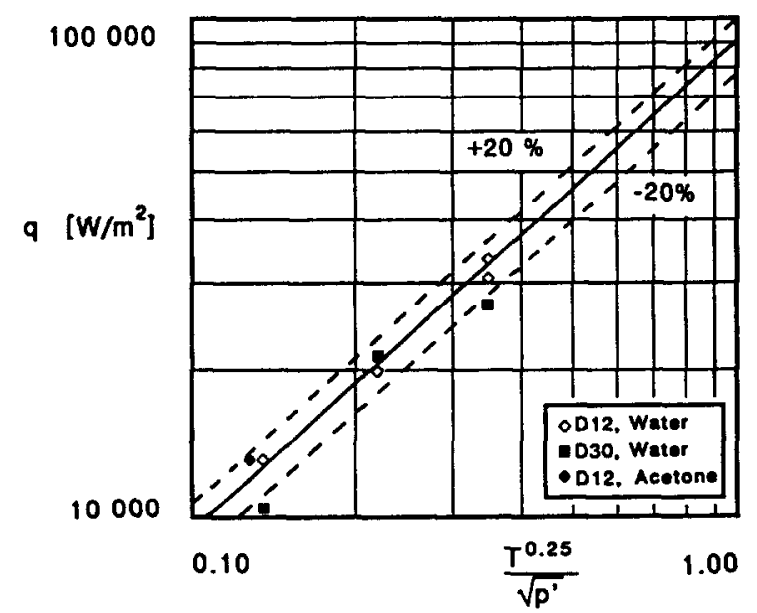

FIG. 6. Plot of experimental vs calculated thermal flux $q_{w_{\ell_{1}}}$ at the transition frontier between intermittent and fully-developed boiling. 


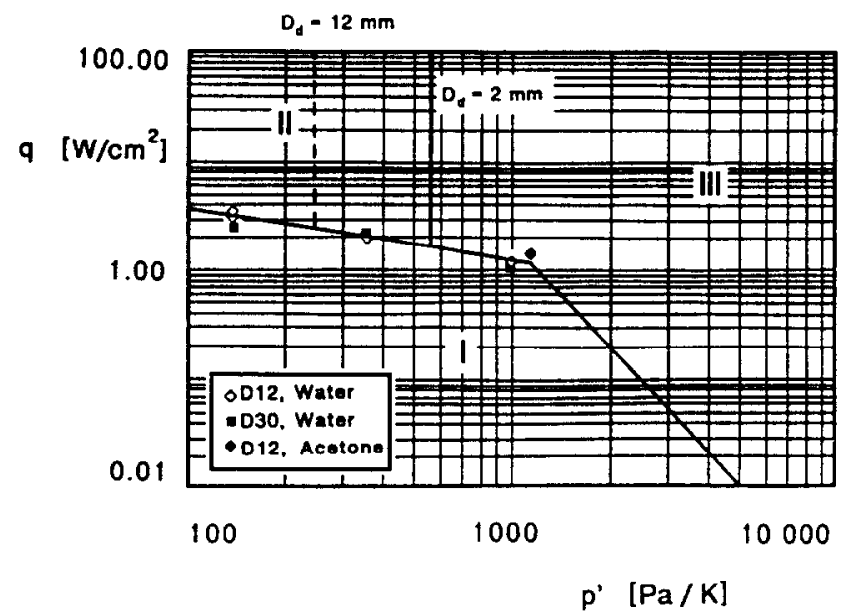

FiG. 7. Frontiers between the main boiling regimes: (I) intermittent boiling; (II) slug-fully-developed boiling: (III) bubble-fully-developed boiling.

Equation (22) is also plotted in Fig. 7 for two bubble diameters, i.e. $D_{\mathrm{d}}=2$ and $12 \mathrm{~mm}$, that satisfy respectively the two criteria $D_{\mathrm{d}} / D \ll 1$ and $D_{\mathrm{d}} / D \sim 1$ for $D=12 \mathrm{~mm}$. The location of the $D_{\mathrm{d}} / D \sim 1$ boundary (dotted line) is only qualitative because it is obviously inconsistent with the assumption $D_{\mathrm{d}} / D \ll 1$ used in deriving the equation for the detachment diameter $D_{\mathrm{d}}$.

In summary, three regions are defined in the $p^{\prime}-q$ plane shown in Fig. 7. In region I we have intermittent boiling (the further we operate from the frontier the lower is the nucleation frequency). In region II we have fully-developed boiling, but the bubbles have dimensions comparable to the device dimension (slugfully-developed-boiling regime). In region III we have bubble-fully-developed boiling, characterized by thick jets of small bubbles. It is noteworthy that the righthand branch of the frontier cannot be extended indefinitely to low thermal fluxes, because eventually it crosses the frontier, not plotted, between boiling and natural convection. Of course, the three regions are bounded in the upper part by a fourth region, not plottcd, where the thermosyphon cannot operate due to the onset of some critical condition or operating limit as flooding. Finally, the $p^{\prime}-q$ plane is perfectly equivalent to a $p-q$ or $p_{\mathrm{r}} \rightarrow q$ plane, since the saturation pressure is a monotonic and convex function of temperature. Here, we have chosen the variable $p^{\prime}$ rather than $p$ so as to avoid empirical or numerical relations in equations (16), (17) and (22).

\section{CONCLUSIONS}

Especially at low pressures, the performance of a closed two-phase thermosyphon with medium and large filling is characterized by unsteady operation. Our analysis and experimental data show that the reason for such unsteady operation is to be found in the boiling mechanisms. Boiling may occur with a wide spectrum of different nucleation frequencies and bubble dimensions depending on liquid superheat, vapor density and other thermodynamic properties.

We classify the boiling regimes on the basis of the frequency of bubble nucleation and the ratio of bubble diameter to device diameter. A criterion for the intermittent/fully-developed-boiling frontier is based on the ratio of the bubble-nucleation waiting time and the bubble growth time. From this criterion we obtain a correlation between power throughput, workingfluid pressure and nucleation critical superheat (equation (15)). This correlation explains the known empirical observation that intermittent boiling regimes are related to low operating pressures. A correlation for slug/bubble-boiling frontier is also derived (equation (22)).

An experimental analysis performed on transparent devices using mainly water as the working fluid yields the dependence of nucleation frequencies on power throughput and operating pressure. The data are in good agreement with the proposed correlation in the dynamic limit (equation (16) or (23)) for the frontier between intermittent boiling and fully-developed boiling except for the constant $G$ which is evaluated experimentally. More data spanning a broader range of operating conditions and including measurements of local superheat, are needed to further validate our theoretical considerations. Also, data on bubble growth in constrained geometries are needed in order to better determine the bubble dimensions at detachment and extend the validity of our results. Finally, work is needed to evaluate the usefulness of power spectrum analyses and phase-plane analyses to better characterize the bubble nucleation frequency.

Acknowledgements - The authors wish to thank Prof. Mario Silvestri and Prof. P. A. Andreini for their helpful suggestions and critical discussions. This research was supported by ENEA. the Italian national committee for the research on Nuclear Energy and Alternative Energies. 


\section{REFERENCES}

1. H. Imura, H. Sasaguchi and H. Kozai, Critical heat flux in a closed two-phase thermosyphon, Int. J. Heat Mass Transfer 26, 1181-1188 (1983).

2. F. Dobran, Steady-state characteristics and stability thresholds of a closed two-phase thermosyphon, Int. J. Heat Mass Transfer 28, 949-957 (1985).

3. J. G. Reed and C. L. Tien, Modeling of the two phase closed thermosyphon, ASME J. Heat Transfer 109, 722 (1987).

4. B. S. Larkin, An experimental study of two-phase thermosyphon tube, Trans. Can. Soc. Mech. Engng 14, 1724 (1971).

5. M. K. Bezrodnyi and D. V. Elekseyenko, Boiling heat transfer in a closed two-phase thermosyphon, Heat Transfer-Sov. Res. 9, 14-20 (1977).

6. T. Fukano, K. Kadoguchi and C. L. Tien, Oscillation phenomena and operating limits of the closed two-phase thermosyphon, Proc. 8th IHTC, Vol. 5, pp. 2325-2330 (1987).

7. C. Casarosa, E. Latrofa and A. Shelginski, The geyser effect in a two-phase closed thermosyphon, Int. J. Heat Mass Transfer 26, 933-941 (1983).

8. Y. Y. Hsu, On the size range of the active nucleation cavities on a heating surface, ASME J. Heat Transfer 84, 207 (1962)

9. C. Y. Han and P. Griffith, The mechanism of heat transfer in nucleate pool boiling-1. Bubble initiation, growth and departure, Int. J. Heat Mass Transfer 8, 887-904 (1965).

10. A. Niro, A study of closed two-phase thermosyphons, Doctoral Thesis, Politecnico di Milano, Milano, Italy (1987).

11. J. S. Saini, C. P. Gupta and S. Lal, Effect of Jakob number on forces controlling bubble departure in nucleate bubble boiling, Int. J. Heat Mass Transfer 18, 472-474 (1975).

12. A. P. Hatton, D. D. James and T. L. Liew, Measurement of bubble characteristics for pool boiling from single cylindrical cavities. In Heat Transfer 1970. Elsevier, New York (1970).

13. C. P. Witze, V. E. Schrock and P. L. Chambré, Flow about a growing sphere in contact with plane surface, Int. J. Heat Mass Transfer 11, 1637-1652 (1968).

14. B. B. Mikic, W. M. Rohsenow and P. Griffith, On bubble growth rates, Int. J. Heat Mass Transfer 13, 657-666 (1970).

15. S. J. D. Van Stralen, R. Cole, W. M. Sluyter and M. S. Sohal, Bubble growth rates in nucleate boiling of water at subatmospheric pressures, Int. J. Heat Mass Transfer 18, 655-669 (1975).

16. W. Zijl, F. J. M. Ramakers and S. J. D. Van Stralen, Global numerical solutions of growth and departure of a vapor bubble at a horizontal superheated wall in a pure liquid and a binary mixture, Int. J. Heat Mass Transfer 22, 401-420 (1979).

17. R. Cole and H. L. Shulman, Bubble growth at high Jakob numbers, Int. J. Heat Mass Transfer 9, 1377-1390 (1966).

18. P. Griffith and J. D. Wallis, The role of surface conditions in nucleate boiling, Chem. Engng Prog. Symp. Ser. 56, 49 (1960).

19. A. M. Kiper, Minimum bubble departure diameter in nucleate pool boiling, Int. J. Heat Mass Transfer 14, 931-937 (1971).

20. J. K. Stewart and $R$. Cole, Bubble growth rates during nucleate boiling at high Jakob numbers, Int. J. Heat Mass Transfer 15, 655-663 (1972).

21. S. J. D. Van Stralen, M. S. Sohal, R. Cole and W. M. Sluyter, Bubble growth rate in pure and binary systems : combined effect of relaxation and evaporation microlayers, Int. J. Heat Mass Transfer 18, 453-467 (1975).

\section{APPENDIX}

During bubble growth, the vapor pressure is related to the motion of the liquid-vapor interface and the mass and energy flux through it. For a spherical bubble growing on a surface in a uniformly superheated liquid at temperature $T_{f_{x}}$ and pressure $p_{\mathrm{f}}$, the momentum and energy equations are

$$
4\left(R \ddot{R}+\dot{R}^{2}\right) \ln \left(\frac{R}{R_{0}}\right) \cos ^{2} \frac{\Phi}{2}+4 R^{2} \cos ^{2} \frac{\Phi}{2}=\frac{p_{g}-p_{f}}{\rho_{f}}-\frac{2 \sigma}{\rho_{f} R}
$$

$$
T_{\mathrm{f}_{\mathrm{x}}}-T_{\mathrm{g}}=\frac{\rho_{\mathrm{g}} h_{\mathrm{fg}}}{k_{\mathrm{f}}} R \sqrt{ }(\pi a t) .
$$

Equation (A1) is that derived by Witze et al. [13] for inviscid and irrotational flow. Unlike the case of bubble growth in infinite geometry, the vapor pressure depends on the angle at center $\Phi$ and has a maximum at the bubble top $(\Phi=0)$. The vapor. for its high diffusivity, may be assumed to be at saturation conditions, i.e. $p_{\mathrm{g}}=p_{\mathrm{s}}\left(T_{\mathrm{g}}\right)$. Assuming

$$
\frac{2 \sigma}{p_{\mathrm{f}} R} \ll 1
$$

the right-hand side of equation (Al) may be simplified to

$$
\text { RHS }=\frac{p_{g}-p_{f}}{\rho_{f}}
$$

or, equivalently

$$
\begin{aligned}
\text { RHS } & =\frac{1}{\rho_{\mathrm{f}}}\left[p_{\mathrm{s}}\left(T_{\mathrm{f}_{\mathrm{x}}}\right)-p_{\mathrm{f}}\right]\left(1-\frac{p_{\mathrm{s}}\left(T_{\mathrm{f}_{\mathrm{x}}}\right)-p_{\mathrm{z}}}{p_{\mathrm{s}}\left(T_{\mathrm{f}_{\mathrm{x}}}\right)-p_{\mathrm{i}}}\right) \\
& =\frac{\Delta p^{*}}{\rho_{\mathrm{f}}}\left(1-\frac{T_{\mathrm{f}_{\mathrm{x}}}-T_{\mathrm{g}}}{T_{\mathrm{f}_{\mathrm{x}}}-T_{\mathrm{s}}\left(p_{\mathrm{f}}\right)}\right) .
\end{aligned}
$$

Moreover, neglecting the inertial terms, i.e. assuming

$$
\frac{4\left(R \ddot{R}+\dot{R}^{2}\right) \ln \left(R / R_{0}\right) \cos ^{2}(\Phi / 2)+4 \dot{R}^{2} \cos ^{2}(\Phi 2)}{\Delta p^{*} / \rho_{\mathrm{f}}} \ll 1 .
$$

Equation ( $\mathrm{Al}$ ) becomes

$$
\frac{T_{\mathrm{f}_{\mathrm{x}}}-T_{\mathrm{g}}}{T_{\mathrm{f}_{\mathrm{x}}}-T_{\mathrm{s}}\left(p_{\mathrm{f}}\right)} \approx 1 .
$$

Thus, bubble growth is controlled only by the energy equation, i.e.

$$
T_{\mathrm{f}_{\mathrm{x}}}-T_{\mathrm{s}}\left(p_{\mathrm{f}}\right)=\frac{\rho_{\mathrm{g}} h_{\mathrm{fg}}}{k_{\mathrm{f}}} \dot{R} \sqrt{ }(\pi a t)
$$

which yields equation $\left(9^{\prime}\right)$ where $\theta=T_{f_{x}}-T_{s}\left(p_{i}\right)$. Using equation $\left(9^{\prime}\right)$, conditions (A3) and (A4) become

$$
\begin{gathered}
\frac{2 \sigma}{p_{f} c J a \sqrt{ }(a t)}+\frac{2 \sigma}{p_{f} c J a \sqrt{ }\left(a \tau_{\mathrm{g}}\left(t / \tau_{\mathrm{g}}\right)\right)} \ll 1 \\
\frac{c^{2} J a^{2}(a / t)}{\Delta p^{*} / \rho_{\mathrm{f}}}+\frac{c^{2} J a^{2}\left(a / \tau_{\mathrm{g}}\right)}{\left(t / \tau_{\mathrm{g}}\right) \Delta p^{*} / \rho_{\mathrm{f}}} \ll 1 .
\end{gathered}
$$

Assuming that conditions ( $\left.\mathrm{A3}^{\prime}\right)$ and $\left(\mathrm{A4}^{\prime}\right)$ hold at the beginning of bubble growth, i.e. for $t \ll \tau_{\mathrm{g}}$, and using equation (12) for $\tau_{8}$ we obtain

$$
\begin{aligned}
& p_{f} \gg \frac{2 \sigma}{\frac{t}{\tau_{\mathrm{g}}}\left(\frac{3 \sigma R_{\mathrm{s}} \sin \Phi}{2 \rho_{\mathrm{f}} g}\right)^{1 / 3}} \approx 2000 \mathrm{~Pa} \\
& J a \ll\left(\frac{1}{c^{2} a^{2}}\left(\frac{3 \sigma R_{\mathrm{s}} \sin \Phi}{2 \rho_{\mathrm{f}} g}\right)^{2 / 3} \frac{\Delta p^{*}}{\rho_{\mathrm{f}}} \frac{t}{\tau_{\mathrm{g}}}\right)^{1 / 4} \approx 25
\end{aligned}
$$

where we used the values $c_{1}=1.5$ and $R_{4}=\left(3 \sigma R_{\mathrm{s}}\right.$ $\left.x \sin \Phi / 2 \rho_{\mathrm{f}} g\right)^{1 / 3}=0.3 \mathrm{~mm}$ taken from the literature [15, 19]. Condition $\left(A 3^{\prime \prime}\right)$ is satisfied in most situations. Thus, con- 


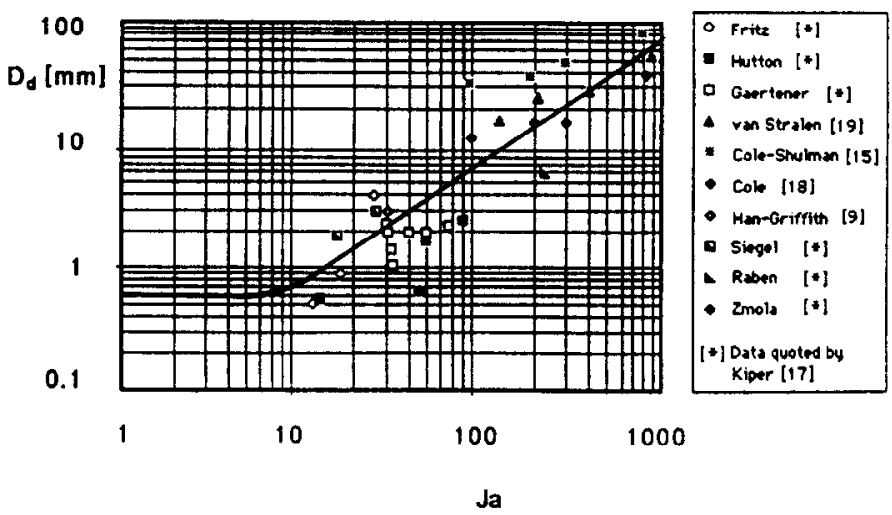

FIG. Al. Plot of equation (20) and experimental data taken from the literature.

dition (A4") implies that the 'diffusive' solution (equation $\left(9^{\prime}\right)$ ) is valid for $J a \leqslant 3$. A large collection of data taken from the literature $[9,12,17,19,20,21]$ show good agreement with the empirical solution $\left(9^{\prime \prime}\right)$ for $J a \geqslant 10$ provided we take $c_{0.75}=2$. The constant $c_{3}$ may be obtained by a best fit of equation (20) on the same experimental data. Since the largest error made using equation $\left(20^{\prime}\right)$ (dynamic limit) to calculate the detachment diameter instead of equation (20) (general solution) for $J a \geqslant \widetilde{J}_{a}$ is less than $25 \%$, it is simpler to use equation $\left(20^{\prime}\right)$. i.e.

$$
R_{\mathrm{d}_{1}}=c_{m}^{4 / 3} c_{3}^{1 / 3}\left(\frac{a^{2}}{g}\right)^{1 / 3} J a^{(4 / 3) m}
$$

Thus, we get $c_{3}=1.228$. Figure Al shows the literature data and equation (20) plotted using the values for constants $c_{0,75}$, $c_{3}$ and $D_{\mathrm{d}_{2}}$ as reported above.

\title{
REGIMES D'EBULLITION DANS UN THERMOSIPHON DIPHASIQUE FERME
}

Résumé-Des résultats expérimentaux et un modèle analytique sur les mécanismes d'ébullition dans un thermosiphon diphasique fermé sont présentés pour définir les frontières entre les régimes principaux d'ébullition et, en particulier, la frontière entre ébullition intermittante et ébullition pleinement développée. Les régimes d'ébullition sont classés sur la base des fréquences de nucléation de bulles. Un critère pour la frontière signalée plus haut est basé sur le rapport du temps d'attente de la nucléation au temps de croissance de la bulle. A partir de ce critère, on obtient une relation entre la puissance fournie, la pression du fluide de travail et la surchauffe critique de nucléation. Des données expérimentales sur les conditions opératoires, les températures et les fréquences de nucléation ont la même dépendance fonctionnelle que pour la relation proposée.

\section{SIEDEBEREICHE IN EINEM GESCHLOSSENEN ZWEIPHASENTHERMOSYPHON}

Zusammenfassung-Es werden experimentelle Ergebnisse und ein analytisches Modell für den Siedemechanismus in einem geschlossenen Zweiphasenthermosyphon vorgestellt, um die Fronten zwischen den Hauptsiedebereichen und-insbesondere-die Front zwischen dem intermittierenden und dem voll entwickelten Sieden zu beschreiben. Die Siedebereiche werden klassifiziert auf der Grundlage der Frequenz der Blasenbildung und des Verhältnisses zwischen Blasendurchmesser und Rohrdurchmesser. Ein Kriterium für die Grenze zwischen dem intermittierenden und dem voll entwickelten Sieden beruht auf dem Verhältnis zwischen der Wartezeit bei der Blasenbildung und der Wachstumszeit. Aus diesem Kriterium ergibt sich eine Korrelation zwischen dem transportierten Wärmestrom, dem Druck des Arbeitsstoffes und der Úberhitzung beim Sieden. Meßdaten für die Betriebsbedingungen, die Temperaturen und die Frequenzen

der Blasenbildung zeigen die gleiche funktionale Abhängigkeit wie die vorgeschlagene Korrelation.

\section{РЕЖИМЫ КИПЕНИЯ В ЗАМКНУТОМ ДВУХФАЗНОМ ТЕРМОСИФОНЕ}

\begin{abstract}
Аппоташ-Представлены зкспериментальные результаты и аналитическая модель механизмов кипения в замхнутом двухфазном термосифоне с целью определения траниц мехду основными рехсимамн хипения, в частности, мехду прерывистым и полностью развитым кипением. Рехимы кипения класснфнцируются на основе частоты образования пузирьхов и отношения их диаметра к диаметру устройства. Критернй границы мехду прерывистим п установившимся кипением базируется на отношенин времени охидания х времени роста. По данному хритерио получены зависимости мехду пропускной мошностью, давлением рабочей жидкости в хрнтическим перегревом при образованни пузырыхов. Функциональная зависимость зхсиериментальньх данных по рехимным параметрам, температурам и частотам образования пузырьков идентична предложенному соотношению.
\end{abstract}

